\title{
Compatible Organization Designs in a Volatile Organizational Context
}

\author{
$1^{\text {st }}$ Sabilil Muttaqin ${ }^{1}$ \\ \{sabil.arjumand@gmail.com ${ }^{1}$ \} \\ UIN Syarif Hidayatullah Jakarta ${ }^{1}$
}

\begin{abstract}
A volatile environment, to some extent, has triggered organizations to readjusting and re-shaping their structure and service delivery. Thus, a flexible organization design is crucial. This study is a qualitative study that uses literature as the main resource. Some website news and individual experiences are also used as the secondary data for this study. This study intends to propose a compatible model of organization design for highly changeable contexts as well as identify the main characteristics and factors that constitute the design. This study further discusses the possibility of implementing the design in Indonesian contexts, particularly State Islamic University Jakarta. The finding suggests the orchestration of organic adaptive organization design which presumes the absence of a single organization design recipe. Instead, it is contingent upon four inter-related forces: managers, tasks, environment, and subordinates. The design should be well aligned with the quality of work-life (QWL) to create better working conditions.
\end{abstract}

Keywords: organization design, flexible organization design, organic organization design, changeable context, quality of work-life, performance review.

\section{Introduction}

One of the major issues in organizational development is that of organizational change. The issue of organizational change is increasingly becoming important as organizations are significantly influenced by changes occurring in their internal and external contexts. Thus, organizations should adapt and adjust their structures to the changes in their internal and external contexts in order to succeed [1]. Some authors have noted the use of tightly coupled structures and loosely coupled structures [2], [3]. Organizations should manage and create certain structures to address appropriate responses towards the changing contexts. Thus, the study of organizational change becomes a crucial issue in the literature, particularly when it comes to the context of organizational decisions. Therefore, it is important to study the organizational change in the spirit of obtaining various perspectives, considerations, and resources for future policy development [4], [5].

In regard to the above discussion, the literature has noted some practical examples where different organization designs can lead to different performances. It is mainly because the certain organizational design is more suitable for certain types of the organizational environment [6] For instance, Roberts (2007) noted that a well established "HB Company", which has been dominating the market for decades, was out-performed by a newly established company namely "NW Company". The pitfall started when the HB Company retained their previous model of management, which is more bureaucratic and centralistic decision making, in a changing 
environment. Conversely, the "NW Company" has learned and implemented an organizational design that provides more focus on different needs of consumers and avoids excessive bureaucracy.

Another study conducted by Waldersee et al. suggested that organic design has overshadowed mechanistic design in dealing with organizational change. Their study suggested that organic design can cope with both technical-structural and behavioral-social change, while mechanistic design only has the ability to cope with technical-structural change. However, although the mechanistic design is outperformed by organic design, the study suggests that mechanistic organizations can cope with the instability of their environment by identifying technical and structural change [7].

In the Indonesian context, the study of organization design is very limited. One of the most relevant studies is the research conducted by Joko Purwanto [8]. In his research, he explained that the Open University (Universitas Terbuka/UT) has implemented a combination structure of functional organizational structure and geographical division. This could be regarded as an effort of learning organization concept that has been implemented at UT. Further, this research stated that UT has implemented a flexible organizational structure that allows flexible change as a response to its organizational contexts.

Indonesia, as one of the developing countries in Asia, has experienced turbulent moments since the reformation era in 1998. This era has triggered the vast movements of social, cultural, economic, and political contexts of the country. These events, together with other factors such as the fast-growing information and technology and global market effects, have created unstable conditions for most government and private organizations in the country. Organizations are forced to adapt and adjust their structures/designs to the ever-changing context in order to survive. This includes universities such as State Islamic University Jakarta (UIN Jakarta).

The above context has signified the fact that all organizational dimensions are inter-related factors that contribute significantly to the success of organizational performance. It also suggests that certain organizational designs correspond to certain contexts, not others. Thus, it is important to have organizational designs which are flexible enough to adjust to the contexts in which the organizations operate. Another important consideration that supports the significance of this research is the fact that the literature has a very limited record of this type of study conducted in the Indonesian context, particularly in educational settings. Therefore, it is important to fulfill this gap in the literature.

\section{Methodology}

This study extensively uses literature to achieve its aim. The main data used are various journal articles and books, while the method of this study is library research. In addition, some secondary data from Indonesian contexts are used to enrich the analysis, particularly when it comes to the possible application of the study in the Indonesian context. Technically, this study garners all sources related to organization design and identifies the main characteristics and factors which constitute a flexible organization design. The obtained data is then sorted in accordance with its significance toward the study. The analysis is then carried out using content analysis to find patterns and models that constitute a flexible organization design for highly changeable contexts.

This study also discusses the possibility of implementing the design in Indonesian contexts, particularly in State Islamic University Jakarta (UIN Jakarta). Specifically, this study is intended 
to answer the following questions: (1) What are the main factors of organization design? (2) What are the main features of a flexible organization design? (3) How is the possibility of applying the design in UIN Jakarta context?

The significance of this study is twofold. First is its contribution to the existing literature, in the sense that it seeks to identify and highlight the main characteristics of a compatible organizational design to highly changeable contexts. The second is the practical aspect of the study. The study outlines a model of organizational design which is suitable to some organizational contexts, particularly to Indonesian contexts.

\section{Result and Discussion}

Most studies on organizational change start from the assumption that an organization should constantly change in regard to the changes in its internal and external contexts [9], [10]. The assumption has, to some extent, stimulated quite extensive research about organizational change. Some of the studies are concerned with the importance of leadership as an effective contributor to the effectiveness and success of organizational change [11], [12]. Other studies are concerned with understanding the context of change and identifying the factors which enable or disable the initiative of change [13], [14]. On the other hand, other studies, see a bigger picture in understanding organizational change by studying organizational designs and their contexts [6], [15]. This study supports the last proposal mentioned. In this instance, this study illustrates the findings and discussion into five main themes to answer the research questions.

\subsection{Key Concepts in Organization Design}

One of the most prominent concepts discussed in the literature is understanding the organization design itself. The definitions of organization design are diverse and stressed on certain matters. However, most of the definitions have highlighted three important accounts. First, the term "organization design" covers both the process and the design, which is organizational structure. Second, organization design is subject to response and is highly dependent upon its contexts, both internal and external. Third, organization design could affect organizational performance.

In his contribution, Richard L. Daft proposed a comprehensive definition that perceives organization design as a formal, guided process in which management achieves the right combination of differentiation and integration of the organization's operations in response to the level of uncertainty in its external environment. Through the design process, organizations act to improve their capacity and performance in order to optimize their service delivery [6]. Daft's definition of organization design is adopted as the operational definition in this study because it covers all the important aspects of the concept concerned.

Another important aspect that should be taken into consideration is strategic direction. Daft [6] emphasizes the importance of the strategic direction process because a good and comprehensive strategic direction will lead to the choice of organizational design that is suitable to the contexts where the organization operates. Strategic direction, also referred to as strategic planning, is a comprehensive process that gathers all organizational contexts, analyzes, and synchronizes the contexts in regard to resource availability in order to fulfill organizational goals, vision, and mission. 


\subsection{Two Poles of Organizational Design: Mechanistic and Organic}

The first organization theory formulated by Weber and Taylor has shown a bureaucratic and mechanistic design of organization [16]. However, as the contexts of the organizations change, the development of organization theory has outlined a model of organization design that resembles living organisms in the sense that it gives such a response and adjusts to the changing environment [6].

Mechanistic design is characterized by organizations that use the closed system and formal structure, while the organic organization is based on an open system with a flexible structure. Similarly, in terms of tasks, the organic organization has low structured tasks while the mechanistic one has high structured tasks. Moreover, Mechanistic organizations tend to base their tasks on habitual operations, while organic organizations prefer to develop problemsolving systems that are based on the uncertainty of the external environment. Thus, the dichotomy of organization design can be seen as mechanistic in one pole and organic in another pole [17].

As has been noted above, organizational structure can be classified into two major structures: tightly coupled system and loosely coupled system. In this regard, mechanistic design tends to operate within structures that are highly bureaucratic and the chain of command is vertically aligned to the system. Conversely, organic design is situated within organizational structures where communication and coordination are more horizontal in nature [6], [18].

Most literature classifies the organizational structure into three main categories: functional structures (vertical), departmental structures, and matrix structures (horizontal) [6], [18]. In addition, the structures regarding the chain of command and communication style could be illustrated in a continuum (see figure 1). The figure displays the type of chain of command operating in the organization ranging from very high command (vertical structure) to low command (horizontal structure).

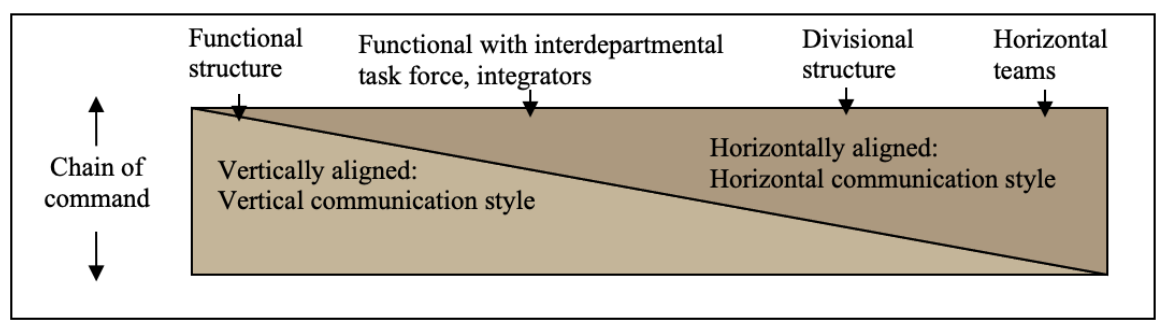

Fig. 1. Continuum Organizational Structure 


\begin{tabular}{|c|c|c|c|}
\hline \multirow{4}{*}{ 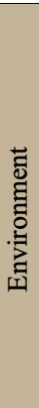 } & \multicolumn{3}{|c|}{ Organizational structure } \\
\hline & & Vertical structure & Horizontal structure \\
\hline & 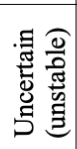 & $\begin{array}{l}\text { Incorrect fit: } \\
\text { Vertical structure in uncertain } \\
\text { environment } \\
\text { Mechanistic structure too tight }\end{array}$ & $\begin{array}{l}\text { Correct fit: } \\
\text { Horizontal structure in uncertain } \\
\text { environment }\end{array}$ \\
\hline & 署焉 & $\begin{array}{l}\text { Correct fit: } \\
\text { Vertical structure in certain } \\
\text { environment }\end{array}$ & $\begin{array}{l}\text { Incorrect fit: } \\
\text { Horizontal structure in certain } \\
\text { environment } \\
\text { Organic structure too loose }\end{array}$ \\
\hline
\end{tabular}

Fig. 2. Relationship Between Environment and Organizational Structure

Furthermore, a model to choose appropriate organizational structure in accordance with its external environment (figure 2). According to the model vertical structure (mechanistic structure) could be a good choice in a stable environment, not in uncertain environment (unstable). On the other hand, horizontal structure (organic structure) might not be suitable for a stable environment but is highly recommended for the uncertain and changeable environment.

However, the recent development of organizational structure is heading towards the combination of both vertical and horizontal structures, such as hybrid structures. It is mainly because the formulation of organizational structure should take into account other factors such as external environment, technology, organizational size, and resource availability [6], [19]. Thus, the structure could be vertically aligned to the system in a certain division, such as production line, and horizontally coupled in another division, such as research and development. In many cases, this combination is intended to achieve two main agenda which are efficiency and development because efficiency can be achieved through systematic control while development can be gained from learning and adaptation to the existing environment.

\subsection{Organic Adaptive Organization Design and Organizational Performance}

Organizational performance is affected by many factors such as leadership, organization structure, internal and external contexts, and organizational culture [11]. One of the factors is the design of the organization. Organization design can affect organizational structure which, to some extent, shapes the organization in the way it operates. Certain types of organization designs may lead the organization to perform better than others [6].

Furthermore, organization design and organizational performance, to some extent, lead to the two main concepts of organization design: tightly coupled system (mechanistic) and loosely coupled system (organic). A tightly coupled system refers to the "extent to which the organization is finely tuned to maximize performance against a particular strategy and environment, whereas, the loosely coupled system is designed to work reasonably well in the face of change" [20, p. 68].

In this notion, it is important to consider the "contingency model of organization design (organic adaptive organization design)" which presumes that there is no single organization design recipe. Instead, the design is contingent upon four inter-related forces within the organization's contexts: forces in the managers, forces in the tasks, forces in the environment, and forces in the subordinates. Furthermore, the design should be organically aligned with the organization's structure and adaptively absorb its external contexts. To do so, the organization 
should, first, have a comprehensive and flexible organizational planning process, a contingency model of strategy formulation.

\subsection{Organic Adaptive Organization Design: Process and Structure}

The previous section has highlighted and proposed an organizational design that is compatible with highly changeable contexts, organic adaptive design. Practically, the process of formulating the design begins with considering previous performance, synergizing it with resource availability and organizational goals and objectives, developing flexible planning, creating multiple measurement systems, and evaluating the outcomes for future performance. More importantly, the design should be perceived as a cyclical process of need analysis, planning, actuating, and evaluating.

To enrich the discussion, it is important to discuss and outline three important elements of organic adaptive organizational design that have been mentioned earlier. Specifically, the discussion will circulate around the use of two prominent strategic directions: strategic planning and strategic incrementalism, as well as the use of performance review and quality of work-life (QWL) programs as a means of identifying and auditing organizational resources and measuring organizational performance. The two important features will then be synergized with the appropriate use of organizational structure. Finally, it will discuss the possible implementation of the design in State Islamic University Jakarta Indonesia (UIN Jakarta) contexts.

\subsubsection{The process: between strategic planning and strategic incrementalism}

In the light of the formulation of strategic planning. Some theorists believe that the strategy should be deliberately formulated to shape organization action in order to achieve organizational goals, vision, and mission [21]. However, other theorists suggest strategic direction often emerges from organizational action [22]. Thus, two types of strategic planning formulation could be noted: deliberate strategy and emergent strategy.

The term 'deliberate' refers to 'an intentional and intended action'. Thus, deliberate strategy is a strategy that involves planning and implementation of the plan [22]. In contrast, 'emergence' means 'the process of becoming apparent'. Emergent strategy is a strategy that is shaped through an iterating process of thinking and doing in response to previous results [23].

Proponents of deliberate strategy argue that deliberateness will create direction because there is a concrete and detailed plan involved in the deliberate strategy. The absence of planning and clear direction might result in drift and confusion because members of the organization do not know what they are doing and how to do it [21], [23]. However, emergent strategy proponents argue that the external environment or the future is highly changeable and unpredictable. Therefore, organization must develop an open-mindstrategy that can identify positive and negative circumstances as well as giving appropriate responses to the unforeseen opportunities as they emerge. In this regard, the existence of a detail plan, to some extent, will create some difficulties [24].

Another advantage of planning is comprehensive resource allocation that will lead to optimum results and performance because in the planning process all available information will be evaluated and analyzed in order to choose the most feasible option [21]. Moreover, documented plans will enable top managers to compare and choose the best course of action proposed by their various business units. On the other hand, the emergent strategists focus 
more on giving autonomy to individuals or teams within organization to develop their sense of entrepreneurship in order to pursue innovative initiatives [25].

Good coordination is another benefit of deliberate strategy because everything is planned, scheduled, and maintained. Moreover, the process of planning involves synchronizing different ideas and opinions to achieve a consistent course of action. By doing so, overlapping, conflicting and contradictory behavior will be avoided or at least be well managed. In contrast, the proponents of emergent strategy believe that experimentation is the best way to know everything. They argue that a strategy obtained through the feedback of practical experiments, trial and error, and learning the basic principles of the problems will result in a successful strategy because they are grounded on the actual situations [25].

The advantages mentioned are some of the contradictory nature of deliberate and emergent strategy. Deliberate strategy creates a clear direction of action while emergent strategy promotes open-minded strategy and flexible action in response to the unpredicted future.

Many recent organization theorists assume that the existence of purely deliberate and emergent strategy is almost impossible [23]. The most organizational strategy will be a mixture of emergent and deliberate strategy. Therefore, it is important to combine two important orientations of planning: adaptive and integrative. Adaptive orientation focuses more on creativity. It helps the organization to systematically seek possible opportunities and threats as well as find the best alternative to deal with them. On the other hand, integrative orientation emphasizes control. It helps the organization to narrow the possible options to obtain effective action.

In regard to the above notion, Wilson (2000) in his work 'from scenario to strategic action' proposes the importance of scenario development and its connection with strategic planning and action. Scenarios are perceived as a 'plausible description of alternative future'. This means that scenarios require the existence of different alternatives of organizational action and direction. Moreover, Wilson presumes that the scenario is not an end. It is a management tool to improve the quality of decision making' Wilson, 2000 cited in [22].

Similarly, a scenario is a learning investment that accommodates both current and future thinking. There are four types of scenarios. The first is a scenario that can be called the "official future". This scenario explicitly forecasts what can be done and what can not be done by the organization. The formulation of this scenario is based on the current trends. The second scenario focuses on exploring some possible situations that can go wrong as well as considering major negative events that might occur. The third scenario explores the structures of different situations to predict possible solutions. While the fourth scenario challenges the paradigm of managers about their vision of the future. The scenarios drive organizational action towards the future by exploring different patterns of opportunities and threats.

The concept of scenario development and the combination of adaptive and integrative planning orientation are some efforts of strategic planning theorists that base their assumptions on the contingency model of strategic planning. This model presumes that there is no one best process for building strategy. Instead, the best model of strategy will be based on an analytical process in regard to current resource availability and organization ability as well as allowing some creativity and innovation in response to possible changes in organizational contexts; internal and external [5]. 


\subsubsection{Performance review and quality of work life (QWL)}

The previous section has noted that one of the characteristics of a flexible organization design is that the organization should have multiple measurement systems. It considers multiple dimensions of performance that are identified as the four forces in the organization. The system should be able to synergize all organizational resources and the environment with organizational goals and objectives. To do so, it is important to note the importance of performance management and the quality of the work-life program (QWL). The two concepts proposed, at least, will have two important implications for the organization. First, it will have a measuring system of goal attainment, thus, the performance will be well measured and evaluated. Second, it will provide a better environment for employees to work.

In general, performance management can be defined as an interlocking set of policies and practices designed and operated to enhance organizational performance and achievement through a concentration on individual performance. The system incorporates the creation of a shared vision, establishment of performance objectives, the formal review process, and linking performance evaluation and employee development and rewards [26].

An effective performance review should carefully consider and analyze the internal and external context of the organization before creating measurement systems. Measurement should focus on employee development and rewards, not only on organizational performance [27], [28]. Furthermore, a performance review should be perceived as an integrated part of a performance management system which focuses on reviewing individual performance to achieve better development towards goal attainment. In this regard, the system should comprehensively synergize the organization's mission, goal, and objectives with the objectives of organizational units and individuals. This effort, subsequently, can create mutually agreed activities and performance measurements within organizational elements. Furthermore, this process should be continually evaluated in order to identify performance improvement and development needs, as well as reward best performers [27], [28]

Quality of work life can be understood as programs that are designed to integrate employees' needs with the organization's desire for higher productivity [28]. It includes job security, a better reward system and higher pay, the opportunity for growth, participative groups, and increased organizational productivity. In this context, quality of work life can be perceived as an effort to enhance organizational performance from the perspective of employees [29], [30]

Furthermore, quality of work life programs should be designed congruently with other performance enhancement programs such as performance management review [31]. In fact, good performance management systems should incorporate the basic concept of quality of work life, in terms of considering employee development and their prosperity [28], [32]. Quality of work life should be based on two basic objectives which are: improving working conditions (from the perspective of employees) and achieving greater organizational effectiveness (from the perspective of employers) [29], [33].

The diagram below (figure 3 ) may help in illustrating the thesis concerned: 


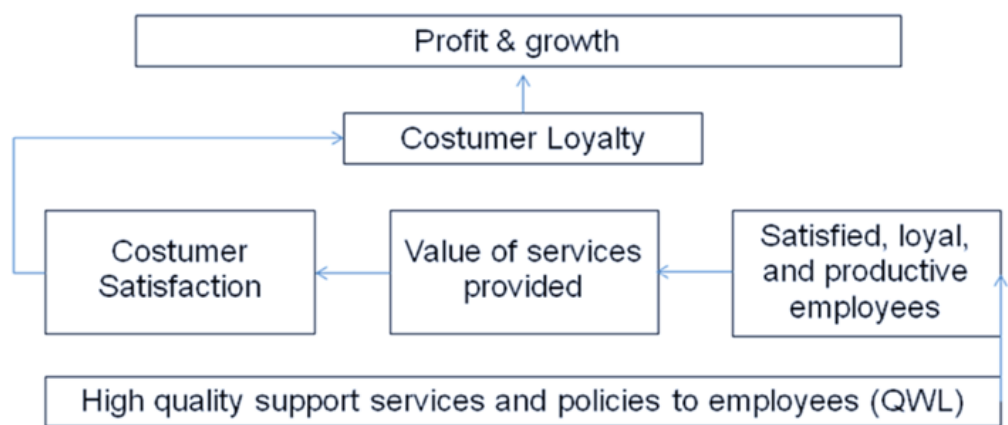

Fig. 3. The Logic Of QWL

In addition, the positive quality of work life can be used as a good recruitment tool. Employees are genuinely attracted by positive support offered by the company such as adequate remuneration, job security, and a friendly working environment. Moreover, good quality of working conditions will decrease absenteeism [34]. A good quality of work life program will also consider the establishment of a Quality Circle. A quality circle is a small group that consists of employees and some managers who meet regularly to identify and solve work-related problems [28]. The type of the circle might vary between one organization and another. However, they commonly share the same objective, which is considering employees' needs in designing organizational tasks.

\subsection{Possible implementation of the design in Indonesian context}

The three sections above have outlined three important components of organic adaptive design, in terms of determining appropriate organizational structure, developing strategic and comprehensive organizational planning, and synergizing the need of all organizational elements in the form of performance management and quality of work life (QWL). It can also be noted that all the discussions lead to the benefit of implementing organic adaptive organization design, particularly in highly changeable contexts.

This study will examine the possibility of implementing the design in Indonesian contexts, particularly in State Islamic University Jakarta Indonesia (UIN Jakarta). To do so, it is important to clarify some important contextual details of the institution which can justify the possible implementation of the design because matching the design with organizational context is very important, otherwise, the design would not be effective [6], [17].

UIN Jakarta has experienced quite significant changes. First, its transformation from an institute into a university in 2002. The transformation has created a more complex organizational situation. Prior to the transformation, the organization only had five faculties with similar concerns which are Islamic-based faculties. Currently, the university has more faculties that cover various disciplines including information and technology, international relations, economics, agribusiness, psychology, and public health, as well as the prior existing faculties. Apart from the educational bodies, the university, in certain ways, is related to some business units such as hotels, business and convention centers, and hospitals. The university is also in the process of becoming a State university with a legal entity (PTNBH) [35].

The organizational context of the university changes from time to time and the structure is complex. Thus, the organization should be organically designed for its internal and external situations. Moreover, the organizational structure should be flexible enough to address any 
situation that occurs. In this case, organic adaptive design, as illustrated in figure 2, could be the best choice for the institution because the organizational context is nicely fitted with the design. The elements of the organic adaptive organization design are outlined in the box on the left of Figure 4, as depicted in the early section. The context of the university as outlined in the box on the right of Figure 4. The author proposes that the closeness of the match between these two boxes indicates that the organic adaptive organization design is the most feasible approach for the University.

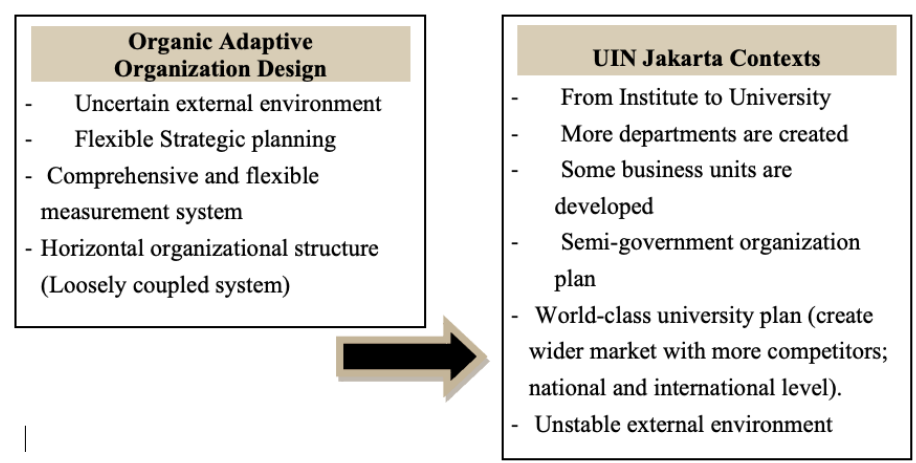

Fig. 4. Matching the design with organizational contexts

Another important aspect is the recent development plan of the university to be a semigovernment institution. This plan will create quite significant changes in both the internal and external context of the organization. Internally, the university should transform its recent organizational structure into different types of structure which fit the new development plan. Externally, the university will be faced with a wider market as well as more competitors, in terms of both government and non-government universities.

Apart from the above context, national and international context may shape and influence the university, particularly as the university is planning to be a world-class university. Thus, the existing global market and the international situation may create the complexity and uncertainty of the external environment. This is aggravated by the uncertainty of national context, in terms of national politics which tends to create uncertainty of government regulation.

In short, the organic adaptive design could be the best choice for the institution, not only because the organizational context is nicely fitted with the design, but also it provides some benefits to the institution. First, the robust structure that is loosely coupled to the management system will enable the organization to respond quickly to the changing environment, as fast decision-making could be achieved. Second, one of the important features of flexible strategic planning, which is scenario development, might provide alternative plans for the organization as the context changes. Third, multiple measurement systems will enable the university to identify and map its resources comprehensively. Thus, the appropriate, and quick response could be delivered. 


\section{Conclusion}

This study highlighted the importance of the contingency model of organization design, organic adaptive organization design. The model presumes there is no single organization design recipe. Instead, the design is contingent upon four inter-related forces within the organization's contexts: forces in the managers, forces in the tasks, forces in the environment, and forces in the subordinates. Moreover, the design should be equipped with an effective performance management system and a good quality of work-life (QWL) programs.

The features of organic adaptive design that have been proposed above are applicable to the Indonesian context, particularly State Islamic University Jakarta Indonesia (UIN Jakarta) because some basic organizational contexts of the institution are highly supportive to the implementation of the concepts concerned.

Conducting primary research is the main source of problem mapping and a strong construct for implementing the design. Studying more than one type of organization, so that the study could propose a framework that provides a practical model for scholars and top managers to choose the type of organization design to their organizational contexts. It is also important to consider the role of leadership in the process of organization design because certain types of leadership would enable the more dynamic process of organizational design.

\section{References}

[1] P. Král and V. Králová, "Approaches to changing organizational structure: The effect of drivers and communication," J. Bus. Res., vol. 69, no. 11, pp. 5169-5174, 2016, doi: 10.1016/j.jbusres.2016.04.099.

[2] R. Pancs, "Tight and Loose Coupling in Organizations," B.E. J. Theor. Econ., vol. 17, no. 1, pp. 38-42, 2017, doi: 10.1515/bejte-2015-0081.

[3] A. Maccormack, C. Baldwin, and J. Rusnak, "Exploring the duality between product and organizational architectures: a test of the "mirroring' hypothesis," Res. Policy, vol. 41, no. 8, pp. 13091324, 2012, doi: 10.1016/j.respol.2012.04.011.

[4] A. Ner, F. Kong, and S. Lluis, "Uncertainty, task environment, and organization design: an empirical investigation," J. Econ. Behav. Organ., vol. 82, no. 1, pp. 281-313, 2012, doi: 10.1016/j.jebo.2012.02.009.

[5] S. Muttaqin, "Implementing Dynamic Capability Framework on Indonesian Schools," J. Iqra' Kaji. Ilmu Pendidik., vol. 6, no. 1, pp. 50-72, 2021.

[6] R. L. Daft, Organization theory and design, 10th ed. Mason, Ohio: Mason, Ohio : South-Western Cengage Learning, 2010.

[7] R. Waldersee, A. Griffiths, and J. Lai, "Predicting Organizational Change Success: Matching Organization Type, Change Type and Capabilities," J. Appl. Manag. Entrep., vol. 8, no. 1, pp. 66-81, 2003.

[8] A. J. Purwanto, "Flexible Organizational Structure for Learning Organization: The Case of Indonesia Open University (Universitas Terbuka)," in Proceedings of the 3Rd International Seminar and Conference on Learning Organization (Isclo-15), 2016, vol. 45, pp. 43-47.

[9] N. Shah, Z. Irani, and A. M. Sharif, "Big data in an HR context: Exploring organizational change readiness, employee attitudes and behaviors," J. Bus. Res., vol. 70, pp. 366-378, 2017, doi: 10.1016/j.jbusres.2016.08.010.

[10] R. Jing, J. L. Xie, and J. Ning, "Commitment to organizational change in a Chinese context.(Report)(Author abstract)," J. Manag. Psychol., vol. 29, no. 8, pp. 1098-1114, 2014, doi: 10.1108/JMP-08-2011-0042.

[11] P. Block, The empowered manager: positive political skills at work, Second edi. Hoboken: 
Wiley, 2017.

[12] G. A. Yukl, Leadership in organizations, 8th ed. Harlow: Harlow : Pearson, 2013.

[13] R. Chia, "On Organizational Becoming: Rethinking Organizational Change," Organ. Sci., vol. 13, no. 5, pp. 567-582, 2002, doi: 10.1287/orsc.13.5.567.7810.

[14] I. Nonaka and R. Toyama, "The knowledge-creating theory revisited: knowledge creation as a synthesizing process," in The essentials of knowledge management, Springer, 2015, pp. 95-110.

[15] J. M. (Jack M. Wood, Organisational behaviour : core concepts and applications, Fifth Aust. Milton Qld : Wiley, 2019.

[16] H. Mintzberg and J. A. Waters, "Of strategies, deliberate and emergent," Strateg. Manag. J., vol. 6, no. 3, pp. 257-272, 1985, doi: 10.1002/smj.4250060306.

[17] D. Samson, Fundamentals of management, 4th Asia P. South Melbourne, Vic.: South Melbourne, Vic. : Cengage Learning, 2012.

[18] R. Pinheiro, L. Geschwind, H. Foss Hansen, and K. Pulkkinen, Reforms, Organizational Change and Performance in Higher Education A Comparative Account from the Nordic Countries, 1st ed. 20. Cham : Springer International Publishing : Imprint: Palgrave Macmillan, 2019.

[19] A. C. Gillon, The nature of contemporary organization development, 1st editio. New York, New York , 2018.

[20] J. Roberts, The modern firm: Organizational design for performance and growth. Oxford university press, 2007.

[21] J. M. Bryson, Strategic Planning for Public and Nonprofit Organizations: A Guide to Strengthening and Sustaining Organizational Achievement., 5th ed.. Newark: John Wiley \& Sons, Incorporated, 2018.

[22] B. De Wit and R. Meyer, "Strategy: Process, Content, Context œ An International Perspective." Thomson Learning, 2005.

[23] J. Kopmann, A. Kock, C. P. Killen, and H. G. Gemünden, "The role of project portfolio management in fostering both deliberate and emergent strategy," Int. J. Proj. Manag., vol. 35, no. 4, pp. 557-570, 2017.

[24] W. Bodwell and T. J. Chermack, "Organizational ambidexterity: Integrating deliberate and emergent strategy with scenario planning," Technol. Forecast. Soc. Change, vol. 77, no. 2, pp. 193 $202,2010$.

[25] S. Soliman, J. Anchor, and D. Taylor, "The international strategies of universities: deliberate or emergent?," Stud. High. Educ., vol. 44, no. 8, pp. 1413-1424, 2019.

[26] A. Nankervis, M. Baird, R. Compton, J. Coffey, and J. Shields, Human Resource Management: Strategy and Practice. Melbourne: Melbourne: Cengage Learning Australia, 2013.

[27] R. A. Noe, J. R. Hollenbeck, B. Gerhart, and P. M. Wright, Human resource management: Gaining a competitive advantage. McGraw-Hill Education New York, NY, 2017.

[28] R. J. Stone, Managing human resources, 3rd ed. Milton, Qld.: Milton, Qld. : Wiley, 2010.

[29] S. S. Bhola, "A study of quality of work life in casting and machine shop industry in Kolhapur," Financ. India, vol. 20, no. 1, 2006.

[30] P. K. Rao and P. Venugopal, "Perceptual factors in quality of work life of Indian employees," Paradigm, vol. 13, no. 1, pp. 104-109, 2009.

[31] S. B. Wikina, "Effective performance improvement and management strategies for the information technology industry," Perform. Improv., vol. 47, no. 9, pp. 19-25, 2008.

[32] R. Levering and M. Moskowitz, "Creating a great place to work: Why it is important and how it is done," Correct. Today, vol. 66, pp. 86-89, 2004.

[33] R. S. M. Lau and B. E. May, "A win-win paradigm for quality of work life and business performance," Hum. Resour. Dev. Q., vol. 9, no. 3, pp. 211-226, 1998.

[34] M. J. Sirgy, D. Efraty, P. Siegel, and D.-J. Lee, "A new measure of quality of work life (QWL) based on need satisfaction and spillover theories," Soc. Indic. Res., vol. 55, no. 3, pp. 241-302, 2001. [35] UIN Jakarta, "UIN Jakarta Prepares Itself to Become PTN BH University," www.uinjkt.ac.id, 2018. 